\title{
Análise dos ganhos econômicos e ambientais da automação industrial para eficiência energética de uma caldeira de lenha
}

Diante das grandes preocupações com as fontes de energias renováveis e os impactos ambientais causados pela indústria, a presente pesquisa apresenta como principal objetivo a automatização de uma caldeira industrial a lenha aumentando sua eficiência energética, diminuindo o consumo de matéria prima e melhorando as emissões de gases poluentes emitidos pela mesma. A metodologia utilizada para o trabalho foi quantitativa, qualitativa e comparativa utilizando cálculos de viabilidade econômica e dados de consumo coletados antes e após a automação proposta; Os principais resultados demonstram que com o uso da automação industrial consegue-se apresentar significativas reduções nos consumos de lenha, melhorias nas questões operacionais e ambientais como também uma melhor eficiência e estabilidade no equipamento pela implantação de um controle automático contínuo em substituição aos antigos meios de operações intuitivos e manuais. O estudo mostrou também que o setor industrial das empresas de produtos lácteos é intensivo no uso de vapor para seus processos fabris.

Palavras-chave: Biomassa; Controle contínuo; Laticínios.

\section{Analysis of economic and environmental gains from industrial automation for energy efficiency of a wood boiler}

\begin{abstract}
In view of the great concerns with the sources of renewable energies and the environmental impacts caused by the industry, the present research has as main objective the automation of an industrial wood boiler increasing its energy efficiency, decreasing the consumption of raw material and improving the emissions of gases pollutants emitted by it. The methodology used for the work was quantitative, qualitative and comparative using economic viability calculations and consumption data collected before and after the proposed automation; The main results demonstrate that with the use of industrial automation it is possible to present significant reductions in the consumption of firewood, improvements in operational and environmental issues as well as a better efficiency and stability in the equipment through the implantation of a continuous automatic control in substitution to the old means of intuitive and manual operations. The study also showed that the industrial sector of dairy companies is intensive in the use of steam for their manufacturing processes.
\end{abstract}

Keywords: Biomass; Continuous control; Dairy.

Topic: Inovação Tecnológica

Reviewed anonymously in the process of blind peer.
Received: 03/04/2021

Approved: 26/04/2021
Valdnere Rosse de Freitas (id

Instituto Federal de Pernambuco, Brasil

http://lattes.cnpq.br/3382031176009315

http://orcid.org/0000-0003-1634-1793

valdnere.rosse@garanhuns.ifpe.edu.br

Luiz Filipe Alves Cordeiro (iD

Instituto de Tecnologia de Pernambuco, Brasil

http://lattes.cnpq.br/4004156784497834

http://orcid.org/0000-0001-8146-9465

filipecordeiro@gmail.com

Daniele de Castro Pessoa de Melo (iD

Instituto de Tecnologia de Pernambuco, Brasil

http://lattes.cnpq.br/4010783198064867

http://orcid.org/0000-0003-4058-092X

daniele.castro@itep.br
Ronaldo Ribeiro Barbosa de Aquino (ic)

Universidade Federal de Pernambuco, Brasil

http://lattes.cnpq.br/0731639653204720

http://orcid.org/0000-0003-4835-7378

ronaldo.ribeiro@ufpe.br

Aldo Torres Sales (iD

Instituto de Tecnologia de Pernambuco, Brasil

http://lattes.cnpq.br/9563136339839657

http://orcid.org/0000-0003-2585-3221

aldo@zootecnista.com.br
Referencing this:

FREITAS, V. R.; CORDEIRO, L. F. A.; MELO, D. C. P.; AQUINO, R. R. B.; SALES, A. T.. Análise dos ganhos econômicos e ambientais da automação industrial para eficiência energética de uma caldeira de lenha. Revista Ibero Americana de Ciências Ambientais, v.12, n.4, p.457-471, 2021. DOI: http://doi.org/10.6008/CBPC2179 6858.2021 .004 .0036 


\section{INTRODUÇÃO}

Com a grande e constante busca pelo desenvolvimento industrial como também a real preocupação com o meio ambiente e a procura por combustíveis alternativos renováveis que seguem tendências crescentes, este devido também à escassez iminente dos combustíveis fósseis, o uso da biomassa têm ganhado destaque no cenário energético para a produção de vapor no uso industrial (SOLA et al., 2015).

Segundo Brand et al. (2015), os combustíveis fósseis como o petróleo, carvão mineral, gás natural ainda são as principais fontes de energia no mundo. Entretanto, além da estimativa de que estas fontes de energia devem se esgotar nos próximos 40 ou 50 anos, os danos ambientais provocados pelas emissões provenientes destas fontes têm impulsionado a humanidade a aumentar a utilização de fontes de energia renováveis, ambientalmente menos nocivas, tais como a solar, eólica e biomassa (KAWÁS, 2014).

A biomassa utilizada como substituta de combustíveis fósseis traz benefícios ambientais, no que se refere à redução das emissões de gases do efeito estufa (GEE) (ALAMIA et al., 2015; MAGALHÃES et al., 2016). $\mathrm{Na}$ forma sólida, este recurso energético responde atualmente por $9,5 \%$ do abastecimento mundial de energia e por 22,9\% da demanda energética brasileira (BRASIL, 2016).

Por sua vez, um dos combustíveis mais utilizados nas caldeiras industriais para produção do vapor é a biomassa constituída de madeiras em geral. A utilização de vapor sob pressão para uso em processamentos diversos, foi uma das maiores descobertas da Revolução Industrial (VERDESOTO, 2019).

A indústria registrou um crescimento no consumo de eletricidade de $1,1 \%$ em relação ao ano anterior; apenas os setores químico, cimento e outras indústrias apresentaram uma variação negativa. (Empresa de pesquisa energética - EPE, Balanço Energético Nacional, 2018). O setor industrial consome $37,7 \%$ da energia elétrica gerada no país.

O setor das indústrias lácteas no Brasil criou 13 mil novos postos de trabalho, mantendo-se como o maior gerador de empregos diretos do Brasil 1,6 milhão. 0 setor brasileiro de alimentos registrou um crescimento de 2,08\% em faturamento no ano de 2018 (TASSI et al., 2019).

Segundo o IBGE (2015), em 2014 foi registrada uma produção de 35,17 bilhões de litros de leite no Brasil, o que colocou o país na sexta posição no ranking mundial, atrás da União Europeia, Índia, Estados Unidos, China e Rússia (USDA, 2015).

Na região Nordeste, a cadeia produtiva do leite tem grande relevância socioeconômica. Porém apresenta dificuldades como baixo nível tecnológico, falta de gestão profissionalizada nas propriedades, limitada capacidade instalada de processamento de laticínios, baixo nível de inovação e pouco dinamismo (MORAIS, 2015).

Segundo o presidente do Sindicato das Indústrias de Laticínios e Produtos derivados do estado de Pernambuco (Sindileite - PE), Carlos Alberto Bezerra diz que o estado abriga cerca de 29 indústrias de grande, médio e pequeno porte cadastradas em 2018, além das chamadas mini-indústrias. 


\section{METODOLOGIA}

Mediante levantamento bibliográfico do tema e coleta de dados In Loco, o trabalho foi estruturado na Indústria Nutrir Produtos Lácteos, localizada na cidade de Gravatá/PE. A Nutrir, um laticínio pernambucano que representa os produtos da marca Natural da Vaca. A empresa mencionada produz diversos produtos tais como: queijos, ricota, leite tipo C, requeijão, fermentados, iogurtes e creme de leite, possui um quadro de 300 funcionários em suas instalações ainda gerando 2.500 empregos indiretos.

De acordo com dados levantados e analisando a relevante importância da empresa para a região, iniciou-se a pesquisa observando problemas do processo produtivo gerados pela instabilidade do fornecimento de vapor, o alto consumo de lenha e a baixa eficiência e rendimento da caldeira industrial como também sua emissão de gases poluentes, estes fatos relatados pela gerência industrial da empresa, então, houve a necessidade de estruturar um projeto de melhoria com potencial energético, econômico e de relevância ambiental.

A caldeira estudada é de marca Maritec Tipo Flamotubular - Categoria B, com pressão de trabalho de $6 \mathrm{Kgf} / \mathrm{cm}^{2}$, pressão de teste $8 \mathrm{Kgf} / \mathrm{cm}^{2}$, pressão de prova $12 \mathrm{Kgf} / \mathrm{cm}^{2}$, capacidade de produção de vapor $2.500 \mathrm{Kg} / \mathrm{h}$, superfície de aquecimento $118,8 \mathrm{~m}^{2}$, de combustível lenha de algaroba. O Quadro 1 apresenta os principais dados da caldeira estudada, estes fornecidos pelo próprio fabricante da mesma.

Quadro 1: Dados técnicos da caldeira.

\begin{tabular}{|l|l|}
\hline Fabricante & Maritec \\
\hline Tipo & Flamotubular \\
\hline Ano de fabricação & 1990 \\
\hline Superfície de aquecimento & $118,8 \mathrm{~m}^{2}$ \\
\hline Produção de vapor & $2.500 \mathrm{Kg} / \mathrm{h}$ \\
\hline Combustível & Lenha \\
\hline Pressão de trabalho & $6 \mathrm{Kgf} / \mathrm{cm}^{2}$ \\
\hline Pressão máxima de trabalho admissível & $12 \mathrm{Kgf} / \mathrm{cm}^{2}$ \\
\hline Pressão de teste hidrostático & $8 \mathrm{Kgf} / \mathrm{cm}^{2}$ \\
\hline Tipo de vapor & Saturado \\
\hline
\end{tabular}

Com a ideia de melhorar a eficiência produtiva da empresa e da caldeira estudada, como o de propor estabelecer um funcionamento do equipamento mencionado ecologicamente correto e menos agressivo tendo como base a crescente preocupação mundial com o meio ambiente, os gases de efeito estufa a as mudanças climáticas se fez necessário uma correta divisão dos estudos da pesquisa.

O estudo distribuísse nas seguintes etapas: Mapeamento e levantamento dos equipamentos que utilizam vapor para produção; Estudo do antigo funcionamento e operação da caldeira; Layout do novo projeto e diagrama de instrumentação; Avaliação financeira da implantação do sistema automatizado; Instalação de um sistema de monitoramento e controle automático contínuo em uma caldeira industrial a lenha; Adequação de uma esteira de alimentação; Analise do processo e dos dados econômicos e ambientais da caldeira estudada; Acompanhamento dos custos para embasar a melhoria dos aspectos econômicos e consumo de matéria prima; 


\section{Mapeamento e levantamento dos equipamentos que utilizam vapor para produção}

Se fez necessário iniciar o trabalho com uma investigação dos equipamentos da fábrica que utilizam o vapor para produção, os mesmos sofriam de grandes variações de pressão e temperatura ocasionando assim muitos problemas de produção.

Realizou-se então um mapeamento dos equipamentos e dos desvios de processo, perdas de produto e paradas de equipamentos os quais geram maior consumo de vapor e comprometimento na qualidade dos produtos fabricados gerando prejuízos nos processos de produção, então foram pesquisados os equipamentos e seus respectivos períodos de trabalho diário.

Com este trabalho temos uma melhor visão de quais os equipamentos consomem mais vapor e assim fazer um cruzamento destas informações com os seus respectivos horários de funcionamento e os picos de maior consumo de vapor realizado pela caldeira estudada.

A Tabela 1. Indica os equipamentos que utilizam o vapor para seu funcionamento junto com os dados de temperatura de entrada, temperatura de saída, tempo de produção, quilograma de cada batelada e suas calorias necessárias para sua produção. A Figura 1 apresenta um gráfico para melhor entendimento dos equipamentos que consomem mais vapor em seu funcionamento.

Tabela 1: Balanço térmico dos equipamentos.

\begin{tabular}{|c|c|c|c|c|c|c|}
\hline EQUIPAMENTO & ENTRADA ${ }^{\circ} \mathrm{C}$ & SAÍDA ${ }^{\circ} \mathrm{C}$ & KG & SEGUNDOS & Kcal necessária & $\begin{array}{l}\text { Potência } \\
\text { Kcal/seg. }\end{array}$ \\
\hline PASTEURIZADOR & 8 & 72 & 6.000 & 2100 & 360960 & 171,89 \\
\hline LEITE & 8 & 78 & 5.000 & 2100 & 329000 & 156,67 \\
\hline PASTEURIZADOR CREME & 50 & 90 & 950 & 2400 & 35720 & 14,88 \\
\hline PADRONIZAÇÃO CREME & 6 & 50 & 950 & 300 & 39292 & 130,97 \\
\hline PASTEURIZADOR & 8 & 78 & 23.600 & 12240 & 1552880 & 126,87 \\
\hline \multicolumn{7}{|l|}{ LEITE } \\
\hline QUEIJOMAT 01 & 35 & 48 & 5.000 & 1200 & 61100 & 50,92 \\
\hline QUEIJOMAT 02 & 35 & 48 & 5.000 & 1200 & 61100 & 50,92 \\
\hline QUEIJOMAT 03 & 35 & 48 & 5.000 & 1200 & 61100 & 50,92 \\
\hline FERMENTEIRA 01 & 45 & 90 & 5.000 & 4200 & 211500 & 50,36 \\
\hline FERMENTEIRA 02 & 45 & 90 & 5.000 & 4200 & 211500 & 50,36 \\
\hline FERMENTEIRA 03 & 45 & 90 & 5.000 & 4200 & 211500 & 50,36 \\
\hline FERMENTEIRA 04 & 45 & 90 & 2.000 & 4200 & 84600 & 20,14 \\
\hline RICOTEIRA 01 & 48 & 90 & 2.000 & 1800 & 78960 & 43,87 \\
\hline RICOTEIRA 02 & 48 & 90 & 2.000 & 1800 & 78960 & 43,87 \\
\hline REQUEIJÃO TRADIC & 30 & 90 & 100 & 600 & 5640 & 9,40 \\
\hline REQUEIJÃO CULINÁRIO & 35 & 90 & 120 & 1800 & 6204 & 3,45 \\
\hline SECADOR DE RALADO & 40 & 78 & 120 & 1800 & 4286 & 2,38 \\
\hline
\end{tabular}

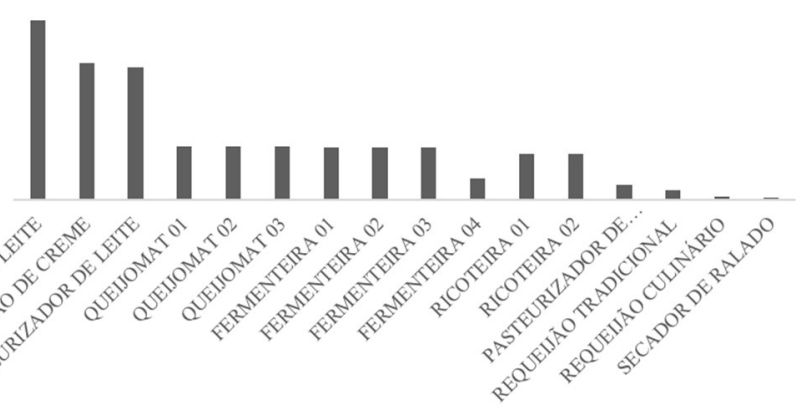

Figura 1: Comparativos dos Consumos de Vapor em Kcal/segundos dos Equipamentos.

Após a realização do levantamento térmico dos equipamentos fez-se necessário utilizar a tabela de 
valores pré-determinados de vapor saturado seco, para que com este trabalho comparamos os valores de capacidade de produção de vapor da caldeira com os utilizados pelos equipamentos da fábrica. A Tabela 2 mostra os valores de temperatura, volume específico saturado e $\mathrm{Kcal} / \mathrm{kg}$.

Tabela 2: Kcal/Kg de Vapor Saturado.

\begin{tabular}{|c|c|c|c|c|}
\hline $\begin{array}{l}\text { Pressão Manométrica } \\
\left(\mathrm{kg} / \mathrm{cm}^{2}\right)\end{array}$ & $\begin{array}{l}\text { Temperatura de vaporização } \\
(\mathrm{C}-)^{\prime}\end{array}$ & Volume específico saturado $\left(\mathrm{m}^{3} / \mathrm{kg}\right)$ & $\begin{array}{l}\text { Vapor } \\
\text { (kcal/kg) }\end{array}$ & $\begin{array}{l}\text { Calor latente de vaporação } \\
(\mathrm{kcal} / \mathrm{kg})\end{array}$ \\
\hline 0 & 99,09 & 1,725 & 638,5 & 539,4 \\
\hline 0,5 & 110,79 & 1,18 & 642,8 & 531,9 \\
\hline 1 & 119,62 & 0,9016 & 645,8 & 525,9 \\
\hline 1,5 & 126,79 & 0,7316 & 648,3 & 521,1 \\
\hline 2 & 132,88 & 0,6166 & 650,3 & 516,9 \\
\hline 2,5 & 138,19 & 0,5335 & 651,9 & 513,1 \\
\hline 3 & 142,92 & 0,4706 & 653,4 & 509,8 \\
\hline 3,5 & 147,2 & 0,4213 & 654,7 & 506,7 \\
\hline 4 & 151,11 & 0,3816 & 655,8 & 503,7 \\
\hline 4,5 & 154,71 & 0,3489 & 656,9 & 501,1 \\
\hline 5 & 158,08 & 0,3213 & 657,8 & 498,5 \\
\hline 5,5 & 161,15 & 0,298 & 658,7 & 496,2 \\
\hline 6 & 164,17 & 0,2778 & 659,4 & 493,8 \\
\hline 6,5 & 166,96 & 0,2602 & 660,2 & 491,7 \\
\hline 7 & 169,61 & 0,2448 & 660,8 & 489,5 \\
\hline 7,5 & 172,11 & 0,2311 & 661,4 & 487,5 \\
\hline 8 & 174,53 & 0,2189 & 662 & 485,6 \\
\hline 8,5 & 176,82 & 0,208 & 662,5 & 483,6 \\
\hline 9 & 179,04 & 0,1981 & 663 & 481,8 \\
\hline 10 & 183,2 & 0,1808 & 663,9 & 478,3 \\
\hline 11 & 187,08 & 0,1664 & 664,7 & 475 \\
\hline 12 & 190,71 & 0,1541 & 665,4 & 471,9 \\
\hline 13 & 194,13 & 0,1435 & 666 & 468,9 \\
\hline 14 & 197,36 & 0,1343 & 666,6 & 466 \\
\hline 15 & 200,43 & 0,1262 & 667,1 & 463,2 \\
\hline
\end{tabular}

\section{Estudo do antigo funcionamento e operação da caldeira}

Após o estudo dos equipamentos e dos seus balanços térmicos a pesquisa foi direcionada para caldeira, nesta foi estudado sua eficiência térmica, mecânica e operacional como também os seus impactos econômicos diretos e indiretos e ao meio ambiente.

Com isso notou-se alguns aspectos relevantes e iniciou-se uma busca para apresentar um método eficaz e eficiente para o seu correto funcionamento. Houve a necessidade de consultar obras pertinentes ao tema, com a finalidade de aumentar a sua eficiência e a confiabilidade dos dados.

Para um melhor entendimento do trabalho, faz-se necessário apresentar imagens de todas as vistas da caldeira. A Figura 2 apresenta uma vista frontal da caldeira estudada. Foi observado em campo e no equipamento a operação e funcionamento da fornalha da caldeira estudada, com isto, percebeu-se que a mesma era operada de forma manual onde a alimentação da matéria prima, neste caso a lenha de algaroba, era feita pelo operador em toras de lenha pesando cerca de 15 a 20 quilogramas cada.

O funcionamento do sistema se realiza da seguinte forma: operador efetua o carregamento das toras de madeira em um carrinho de mão e o transporta até a caldeira onde lá efetuava a abertura da escotilha da grelha utilizando um gancho de metal e lançava manualmente e de forma totalmente intuitiva as toras de madeira no interior da grelha da caldeira, isto era realizado de forma intuitiva pelo operador e sem qualquer monitoramento de temperatura ou padrão de dados, o que levava a caldeira a funcionar de forma totalmente arcaica e sem uma sequência lógica baseada na quantidade da matéria prima ou eficiência do equipamento. 


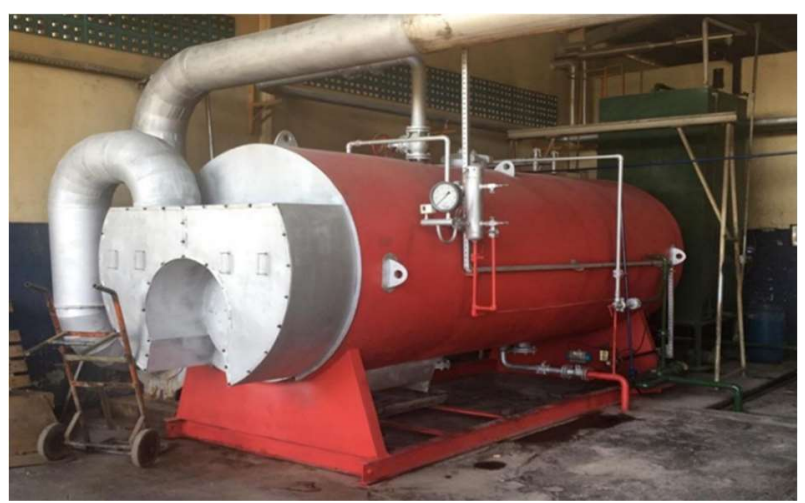

Figura 2: Vista Frontal da Caldeira.

Toda a alimentação da caldeira era realizada manualmente por um operador. Esta atividade submetia o operador a grandes riscos de acidente, riscos ergonômicos e sem um devido controle. Foi constatado que, a caldeira trabalhava em um sistema de controle on-off (liga e desliga) comandada apenas por dois equipamentos, um pressostato de marca danfoss tipo KP1 de regulagem por mola e um sensor de nível de marca coel modelo NI35 operado por eletrodos de referência.

O controle de pressão da caldeira era feito pelo pressostato que em pressões abaixo da regulada aciona os contatos de números 2 e 4 assim ligava o motor do exaustor até atingir a pressão desejada após o pressostato efetuar a abertura dos contatos desligando assim o motor do exaustor da mesma forma o sensor de nível através dos eletrodos instalados no interior do garrafão de nível detecta o nível de água baixo e aciona a bomba de alimentação de água.

Após a caldeira atingir a pressão e a temperatura desejada o operador realiza a abertura da válvula de saída do coletor manualmente de forma lenta para que não haja golpes na linha. Foi verificado que este processo expõe o operador a altas temperaturas e graves riscos de acidentes já seu sistema de controle se torna de baixa eficiência pois causa grandes oscilações pelo fato de ser praticamente liga e desliga havendo grande perda de energia onde o rendimento da caldeira encontra-se muito baixo em cerca de $45 \%$.

Se fez necessário efetuar o levantamento da quantidade de gases nocivos enviados para atmosfera pela chaminé da caldeira (concentrações de monóxido de carbono (CO), de óxidos de nitrogênio (NOx) e de dióxido de enxofre (SO2), os custos financeiros da matéria prima neste caso a lenha de algaroba queimada na caldeira para produção de vapor, os gastos com energia elétrica para tal operação, a quantidade de energia, lenha e água gastas em um determinado período de produção como também atentarmos para os seus ciclos de abastecimento de água e combustível.

Através de dados coletados pelo levantamento dos equipamentos de produção e os seus respectivos balanços térmicos comparados com a capacidade de produção de vapor da caldeira junto com as informações fornecidas pelos operadores e mantenedores constatamos os principais problemas de operação, manutenção e eficiência da caldeira.

Em posse de tais fatos buscou-se comprovar que, com a automação industrial de um equipamento, iria se estabelecer um rol positivo de impacto na caldeira estudada reduzindo seu consumo, melhorando sua eficiência térmica como também nas questões ambientais, trazendo para a discussão, seus impactos positivos, seu uso e suas possibilidades para o futuro. Para tal, foi exposto de maneira sucinta anteriormente 
o panorama do antigo modo de operação e funcionamento da caldeira e como isso, notou-se que havia uma diminuída eficiência e confiabilidade trazendo gastos econômicos significativos bem como material de caráter agressivo jogado diretamente no meio ambiente a partir da geração de gases nocivos. Houve a intenção de consultar obras pertinentes ao tema, com a finalidade de aumentar a confiabilidade dos dados.

\section{Layout do novo projeto e diagrama de instrumentação}

Em função da literatura relacionada ao trabalho e a métodos quantitativos e qualitativos de diagnósticos baseados em dados coletados, o presente trabalho desenvolveu um modelo de implementação da automação industrial.

Foi elaborado um novo layout com base no funcionamento do equipamento estudado e apresentado um novo modelo de funcionamento e operação da caldeira utilizando como ferramenta principal a automação industrial.

\section{Avaliação financeira}

A análise de viabilidade econômica é a ferramenta essencial para analisar qualquer projeto quem tenha o intuito de se tornar executável, logo encontrar o melhor projeto mais eficiente possível no caso em que exista mais de uma alternativa mutuamente excludente, ou no caso individual do projeto, analisar a economia e em quanto tempo o investimento inicial dará retorno desejado.

Saber o retorno do investimento feito inicialmente e em quanto tempo a melhor escolha se paga, ou seja, a opção pode ser mais cara a princípio pode sair como a mais barata com o passar do tempo devido a eficiência energética do projeto, consequentemente o custo total sairá mais barato em longo prazo quando se adicionar o gasto com energia ao preço do produto atual.

\section{Valor Presente Líquido}

O Valor Presente Líquido (VPL) também conhecido como Valor Atual Líquido (VAL) é uma fórmula que analisa a série de pagamentos futuros projetados no momento atual. Nesta análise, levam-se em conta os aspectos que diferenciam os projetos e não os aspectos em que os projetos são iguais, isso significa que o diferencial do projeto será traduzido no VPL, e na comparação entre dois projetos, o maior VPL representa o melhor custo benefício.

Essa formulação é ideal, pois leva em consideração o valor do dinheiro com o passar do tempo, pois a quantia hoje não será a mesma futuramente devida no mínimo a inflação do país. Logo, a Taxa Mínima de Atratividade é usada para comparar investimentos, ela carrega o significado de no mínimo corrigir o valor do dinheiro devido ao tempo que passa. A formulação do cálculo do VPL é apresentada na Equação 1 (SOARES, 2017).

$$
\begin{aligned}
& C=F C /(1+T M A)^{\wedge} n \\
& C=\frac{51000}{(1+0,1)^{1}}=9.090,90 \quad C=\frac{51000}{(1+0,1)^{5}}=6.209,21
\end{aligned}
$$




$$
\begin{gathered}
C=\frac{51000}{(1+0,1)^{2}}=8.264,42 \quad C=\frac{51000}{(1+0,1)^{6}}=5.131,58 \\
C=\frac{51000}{(1+0,1)^{3}}=7.513,14
\end{gathered}
$$

FC - Fundo Capital inicial

TMA - Taxa Mínima de Atratividade (\%) $\mathrm{n}$ - é a periodicidade da análise.

A interpretação do Valor Presente Líquido se dá inicial e basicamente no sinal de VPL, se positivo o investimento é bom, se negativo, a opção não é viável, em seguida analisar os valores de VPL, logo quanto maior o VPL melhor. Em $\mathrm{n}$ igual a 0 corresponde ao investimento inicial que no caso entra no somatório como negativo.

Calculamos um valor de capital inicial do projeto de automação da caldeira em $\mathrm{R} \$ 51.000,00$ (Cinquenta e um mil reais), com um valor de inflação de $10 \%$ ao mês que será tomado como base, o que equivale a 0,1. O valor do retorno financeiro estipulado é de $R \$ 10.000,00$ (Dez mil reais) ao mês em um período de um ano, ou seja, 12 meses. A figura 3 mostra um gráfico do VPL calculado com uma redução máxima de $10 \%$ ao mês e que também nos mostra que mesmo com uma taxa de juros absurda o projeto ainda se torna viável.

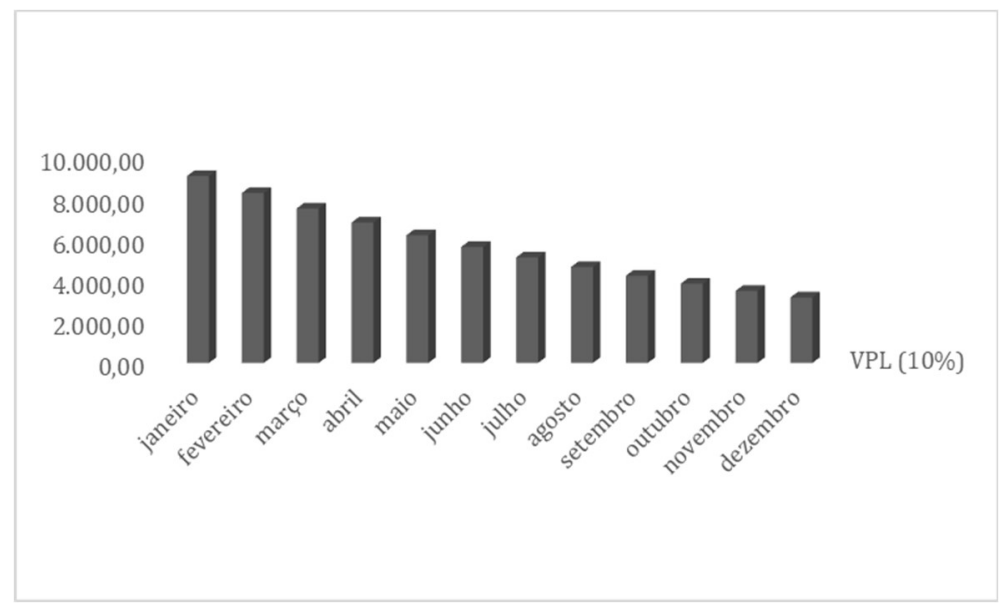

Figura 3: Gráfico VPL.

\section{Tempo de Retorno de Capital}

O critério de retorno de capital, ou payback simples, resume-se em dividir o valor do investimento pelo valor de economia ou lucro sem considerar o horizonte de tempo, logo o dinheiro perde seu valor com o passar do tempo. Essa análise é mais usada em primeira instância, pois ela simplesmente esboça um cenário provável o que não a torna tão discrepante do Valor Presente Líquido. A fórmula do Payback simples está escrita na Equação 10 (SOARES, 2017).

O payback, ou período de payback, refere-se ao tempo que um investimento leva para pagar o seu investimento inicial. O valor médio calculado para o investimento inicial será de $\mathrm{R} \$ 51.000,00$ (Cinquenta e um mil reais) onde a média de retorno mensal calculada segunda a tabela 3.1 será de $\mathrm{R} \$ 13.255,21$ onde o tempo de retorno é dado pela seguinte maneira:

Payback = Investimento Inicial / Ganhos no período 
Tempo de retorno $=$ Investimento Inicial $/$ retorno mensal

Tempo de retorno $=51.000,00 / 13.255,21=3,8$ meses

Conforme o cálculo acima o retorno do investimento se dará em quatro meses considerando um arredondamento para maior tempo, abaixo segue as informações das quantidades e dos principais equipamentos a serem utilizados na automação da caldeira.

\section{Instalação de um sistema de monitoramento e controle automático contínuo}

Após a análise financeira foi proposto a realização da automação da caldeira iniciando-se com a instalação de sensor de temperatura PT100, transmissor de pressão com sinal de saída de 4 a 20MA na linha de saída da caldeira e transmissor de nível por pressão diferencial no corpo da caldeira para que tais equipamentos enviem suas leituras de temperatura, pressão e nível real para o sistema de controle automatizado.

Montagem de novo quadro elétrico e inversores de frequência para modulação das velocidades dos motores dos exaustores com circuitos elétricos comandados por CLP (Controlador Lógico Programável) de marca Delta modelo DVP20SX211T e interagindo com o operador através de uma IHM (Interface Homem Máquina) modelo DOP-B07S410.

Conforme sequência lógica realizamos a programação e parametrização dos equipamentos de controle conforme o funcionamento correto da nova caldeira, o acompanhamento do início do funcionamento da planta industrial após a caldeira estar em plena carga se fez necessário para coletar os dados de consumo de lenha, energia elétrica e a qualidade e quantidade dos gases emitidos na saída da chaminé da caldeira e seus impactos ambientais.

Em virtude dos fatos mencionados anteriormente, foi projetado, dimensionado e efetuado a instalação de um sistema de alimentação automática, feito através de uma esteira transportadora metálica com controle de velocidade feito através de um inversor de frequência de marca WEG modelo CFW500 o mesmo comandado por um CLP (Controlador Lógico Programável). A esteira tem por função efetuar a alimentação de matéria prima para caldeira de forma contínua e controlada sem a necessidade do trabalho manual antes realizado de forma intuitiva pelo operador. Todo o trabalho manual foi substituído por uma esteira transportadora de lenha instalada em substituição ao processo de alimentação antigo, conforme comentado anteriormente.

Sobre o aspecto do sistema elétrico os seus acionamentos de força são realizados por dois motores elétricos distintos, um do exaustor que é um motor de potência de $5 \mathrm{cv}$ e o outro o motor bomba de alimentação hidráulica da caldeira, mas popularmente conhecida com, bomba d'água de alimentação da caldeira que por sua vez é de potência de $3 \mathrm{cv}$ ambos eram acionados em partida direta.

Na Tabela 4 estão os dados técnicos dos motores elétricos da caldeira.

Tabela 4: Dados técnicos dos motores elétricos da caldeira.

\begin{tabular}{|l|l|l|l|l|l|l|l|}
\hline Quant. & Descrição & Marca & Pot. (cv) & Tensão (v) & Corren.(A) & rpm & Partida \\
\hline 01 & Exaustor & Weg & 5 & $220 / 3380$ & $14.1 / 8.19$ & 17251 & Direta \\
\hline 01 & Bomba água & Weg & 3 & $220 / 3380$ & $7.81 / 4.52$ & 3460 & Direta \\
\hline
\end{tabular}


O motor do exaustor da caldeira tem a função de executar a retirada dos gases formados pela queima e aumentar a circulação de ar no interior da caldeira e consequentemente aumento das chamas na grelha. Neste caso propomos a substituição do método de partida elétrica antigo pelo uso de partida e controle de velocidade através de inversor de frequência (WEG CFW-500 5cv - 380v-60Hz) com está ação conseguimos reduzir significativamente seu consumo elétrico pois o mesmo não mas atua no sistema liga e desliga gerando picos de consumo e correntes elétricas em seu acionamento e desgastes nos acoplamentos mecânicos.

Sobre o ponto de vista do processo de produção de vapor pela caldeira o antigo método de acionamento e controle causava bastante instabilidade de pressão na linha gerando um alto consumo de matéria prima e com a automação do processo o exaustor trabalha continuamente modulando sua velocidade pela necessidade de pressão na linha com este trabalho conseguisse eliminar os picos de consumo elétrico, estabilizar a pressão na linha e diminuir o consumo de matéria prima.

Primeiramente realizou-se uma pesquisa bibliográfica, com base em livros atualizados sobre normas regulamentadoras voltadas ao tema, juntamente com definições e características de chaves de partidas elétricas e eletrônicas para motores elétricos, com o intuito de obter embasamento teórico. Com base em um contrato de demanda de energia, realizou-se uma simulação do dimensionamento das chaves de partida dos motores elétricos conforme equações do quadro 4, com o objetivo de reduzir o consumo de energia elétrica no momento da partida dos mesmos, além de aumentar sua vida útil.

Foi necessário calcular a corrente de partida para nortearmos os gastos elétricos da caldeira estudada. O Quadro 4 apresenta a fórmula básica da corrente de partida dos motores nas duas situações, partida direta e com o uso do inversor de frequência. O motor do exaustor foi tomado como referência. $O$ quadro 5 apresenta os cálculos executados.

Quadro 4: Fórmulas para cálculo das correntes de partida nos motores.

\begin{tabular}{|c|c|c|}
\hline CHAVE DE PARTIDA & DIRETA & INVERSOR \\
\hline FÓRMULA & $I p=\frac{I p}{I n} x \operatorname{In}$ & $\begin{array}{c}I p \\
\text { Q }\end{array} \quad$ y \\
Sendo que $\mathrm{y}=(1,2)$
\end{tabular}

Quadro 5: Cálculo das correntes de partida.

\begin{tabular}{|c|c|c|}
\hline CHAVE DE PARTIDA & DIRETA & INVERSOR \\
\hline FÓRMULA & $I p=8,0 \times 8,19=65,52 \mathrm{~A}$ & $\begin{array}{c}I p=8,0 \times 1,2=9,6 \mathrm{~A} \\
\text { Sendo que } \mathrm{y}=(1,2)\end{array}$ \\
\hline
\end{tabular}

\section{RESULTADOS E DISCUSSÃO}

O desenvolvimento e a implementação da automação em ambientes industriais são ferramentas essenciais para a otimização dos sistemas atualmente utilizados. A aplicação de um sistema automatizado em um ambiente industrial deve levar em consideração os seguintes itens: Conhecer o processo industrial onde o sistema será implementado; Conhecer o ambiente e a filosofia aplicada na automação industrial para sugerir uma localização adequada para os equipamentos.

O presente estudo demonstra que as caldeiras industriais e semi-industriais cujo combustível é à base de lenha são consideradas de suma importância para os processos produtivos das indústrias lácteas em 
geral, vendo que a elevação dos preços da energia, o consumo racional é essencial para a sobrevivência das mesmas, pois a disponibilidade do vapor reflete diretamente no desenvolvimento da empresa. Com isso, estudos e avaliações energéticas possibilitam otimizar todo o sistema de geração e distribuição do vapor e a redução dos custos na produção.

Notou-se que, com a automação industrial voltada para eficiência energética de um determinado equipamento, que detém funções primordiais para o bom funcionamento da planta fabril e seus processos produtivos, alcançasse a fundamental importância de reduzir falhas, aumentar sua eficiência e produtividade, minimizar emissões de gases poluentes que impactam diretamente em seus ganhos econômicos e ambientais.

As análises que ocorreram durante a presente pesquisa foram enriquecidas por soluções simples a pequenos problemas imperceptíveis no que se diz respeito a operação em funcionamento deste equipamento como também as questões elaboradas pelo autor e colaboradores locais.

Baseado nestas premissas, o presente trabalho buscou desenvolver uma ferramenta industrial de baixo custo e de fácil implementação, em conformidade operacional com os sistemas de automação e controle comerciais atualmente disponíveis, como alternativa para a análise de gases residuais da queima de uma caldeira que utiliza lenha para queima.

A Tabela 5 apresenta os dados de consumo de lenha com o método de gerenciamento dos recebimentos da matéria prima em quatro meses consecutivos, indicando data, placa do veículo, metro cúbico de lenha por veículo, e valor. Conforme os dados coletados o valor total gasto em reais durante os quatro meses fora de $\mathrm{R} \$ 162.762,93$ isso representa um valor médio por mês de $\mathrm{R} \$ 40.690,73$ onde a empresa recebe cerca de dois caminhões por semana chegando de 06 a 07 caminhões ao mês onde a mesma paga aos fornecedores um valor de $\mathrm{R} \$ 99,00$ por metro cúbico da lenha de algaroba.

Tabela 5: Dados de Consumo de lenha.

\begin{tabular}{|c|c|c|c|}
\hline DATA & VEÍCULO & M3 & VALOR R\$ \\
\hline 04/01/19 & GYR 8031 & 65,91 & $6.525,09$ \\
\hline $11 / 01 / 19$ & GYR 8031 & 66,3 & $6.563,70$ \\
\hline $16 / 01 / 19$ & GYR 8031 & 66,3 & $6.563,70$ \\
\hline 20/01/19 & PFR 6922 & 64,35 & $6.370,65$ \\
\hline 24/01/19 & HHK 1448 & 67 & $6.633,00$ \\
\hline 29/01/19 & PFR 6922 & 66,3 & $6.563,70$ \\
\hline $02 / 02 / 19$ & GYR 8031 & 65,80 & $6.514,20$ \\
\hline $07 / 02 / 19$ & GYR 8031 & 65,71 & $6.505,29$ \\
\hline 09/02/19 & GYR 8031 & 65,31 & $6.465,69$ \\
\hline $14 / 02 / 19$ & PFR 6922 & 66 & $6.534,00$ \\
\hline $17 / 02 / 19$ & GYR 8031 & 62,5 & $6.187,50$ \\
\hline $23 / 02 / 19$ & PFR 6922 & 64 & $6.336,00$ \\
\hline 01/03/19 & GYR 8031 & 65,71 & $6.514,20$ \\
\hline 09/03/19 & HHK 1448 & 67,4 & $6.672,60$ \\
\hline 09/03/19 & PFR 6922 & 67,2 & $6.652,80$ \\
\hline $18 / 03 / 19$ & PFR 6922 & 67 & $6.633,00$ \\
\hline 23/03/19 & GYR 8031 & 66,3 & $6.563,70$ \\
\hline $25 / 03 / 19$ & GYR 8031 & 65,71 & $6.505,29$ \\
\hline 29/03/19 & PFR 6922 & 66 & $6.534,00$ \\
\hline $06 / 04 / 19$ & GYR 8031 & 66 & $6.534,00$ \\
\hline $12 / 04 / 19$ & GYR 8031 & 65,32 & $6.466,68$ \\
\hline $13 / 04 / 19$ & GYR 8031 & 65,32 & $6.466,68$ \\
\hline $18 / 04 / 19$ & GYR 8031 & 65,31 & $6.465,69$ \\
\hline 24/04/19 & GYR 8031 & 65,52 & $6.486,48$ \\
\hline 26/04/19 & GYR 8031 & 65,71 & $6.505,29$ \\
\hline
\end{tabular}


Já a Tabela 6 apresenta os dados de consumo de lenha após a implantação do sistema automático de controle em quatro meses consecutivos. O valor total gasto em reais durante os quatro meses foi de $\mathrm{R}$ $\$ 103.742,10$ isso representa um valor médio por mês de $\mathrm{R} \$ 25.935,52$ onde a empresa receberá cerca de 01 caminhão por semana chegando a 04 caminhões ao mês.

Tabela 6: Dados de consumo de lenha após automação.

\begin{tabular}{llll}
\hline DATA & VEÍCULO & M3 & VALOR R\$ \\
\hline $04 / 06 / 19$ & PFR 6922 & 64 & $6.336,00$ \\
$10 / 06 / 19$ & HHK 1448 & 65,5 & $6.484,50$ \\
$18 / 06 / 19$ & GYR 8031 & 63,8 & $6.316,20$ \\
$24 / 06 / 19$ & HHK 1448 & 65 & $6.435,00$ \\
$03 / 07 / 19$ & PFR 6922 & 66,3 & $6.563,70$ \\
$08 / 07 / 19$ & HHK 1448 & 64.6 & $6.395,40$ \\
$15 / 07 / 19$ & PFR 6922 & 65.3 & $6.464,70$ \\
$22 / 07 / 19$ & GYR 8031 & 66 & $6.534,00$ \\
$05 / 08 / 19$ & HHK 1448 & 67 & $6.633,00$ \\
$12 / 08 / 19$ & HHK 1448 & 65 & $6.435,00$ \\
$19 / 08 / 19$ & GYR 8031 & 64.8 & $6.415,20$ \\
$26 / 08 / 19$ & GYR 8031 & 66 & $6.534,00$ \\
$04 / 09 / 19$ & PFR 6922 & $6.633,00$ \\
$10 / 09 / 19$ & PFR 6922 & 67 & $6.385,50$ \\
$16 / 09 / 19$ & HHK 1448 & 64,5 & $6.534,00$ \\
$23 / 09 / 19$ & GYR 8031 & 66 & 67,90 \\
\hline
\end{tabular}

A Figura 4 apresenta os dados de consumo da lenha de algaroba entre os quatro meses consecutivos antes da implantação do sistema e após a implantação. Já a tabela 7 mostra os ganhos percentuais antes e após a implantação.

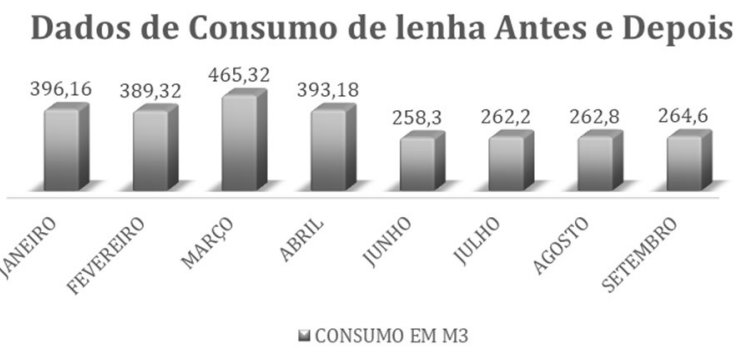

Figura 4:_Comparativo do consumo de lenha após a implantação do sistema.

Tabela 7: Ganhos percentuais.

\begin{tabular}{llllll}
\hline MÊS & VALOR R\$ & MÊS PÓS & VALOR R\$ & REDUÇÃO ( \%) & ECONOMIA R\$ \\
\hline $01 / 19$ & $39.219,84$ & $06 / 19$ & $25.571,70$ & 35 & $13.648,14$ \\
$02 / 19$ & $38.542,68$ & $07 / 19$ & $25.957,80$ & 33 & $12.584,88$ \\
$03 / 19$ & $40.075,59$ & $08 / 19$ & $26.017,20$ & 35 & $14.058,39$ \\
$04 / 19$ & $38.924,82$ & $09 / 19$ & $26.195,40$ & 33 & $12.729,42$ \\
\hline
\end{tabular}

A Figura 5 apresentam os valores entre os quatro meses consecutivos antes da implantação do sistema e após a implantação.

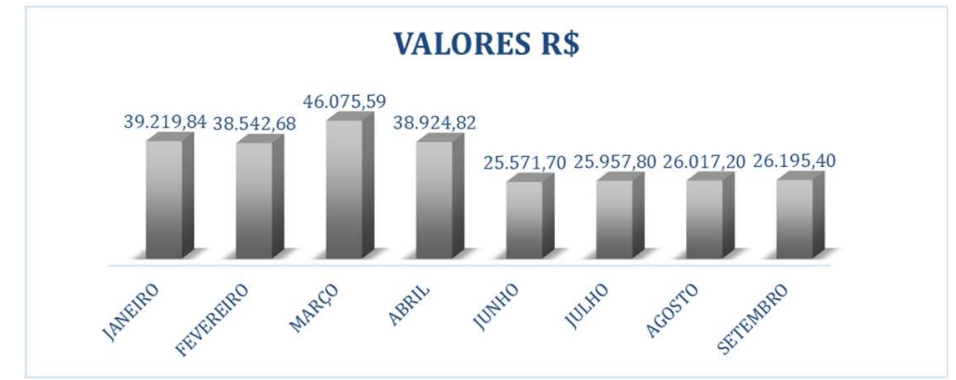

Figura 5: Valores dos ganhos. 
Foi necessário apresentar a relação de equipamentos e suas especificações e quantidades para a realização da implantação da automação na presente pesquisa. O Quadro 6 apresenta a lista de equipamentos necessários e utilizados para a automação do sistema.

Quadro 6: Lista de Equipamentos.

\begin{tabular}{|l|l|l|}
\hline Item & Quant. & Descrição \\
\hline 01 & 01 & Transmissor de Pressão - Ranger = 0 a 100 bar / Saída = 4 a 20 mA \\
\hline 02 & 01 & Transmissor de Nível - Endress Hauser - PMD75 / Saída = 4 a 20 mA \\
\hline 03 & 01 & Sensor de Temperatura - TIPO = Sonda = PT100 / Saída = 4 a 20 mA \\
\hline 04 & 02 & Inversor de Frequência WEG CFW-500 3cv - 380 v - 60Hz \\
\hline 06 & 01 & Inversor de Frequência WEG CFW-500 5cv - 380 v - 60Hz \\
\hline 07 & 01 & CLP DVP 20SX211R \\
\hline 08 & 01 & IHM DOP-107WV \\
\hline 09 & 01 & Válvula de Controle Spirax-Sarco 4" - LEA 43 \\
\hline 10 & 01 & Atuador Pneumático para Válvulas de controle Spirax-Sarco - PN9100 \\
\hline 11 & 01 & Posicionador Eletropneumático EPL - Spirax-Sarco - Entrada 4 a 20mA \\
\hline 12 & 01 & Quadro de comando 1.800x1.000x400mm \\
\hline 13 & 10 & Fonte de corrente continua de 220v/24vcc 8A \\
\hline 14 & 01 & Relé acoplador de 24vcc 1NA/1NF \\
\hline
\end{tabular}

Os principais resultados esperados deste estudo, associado a todos os encontrados na literatura para desenvolvimento deste, demonstraram que com o uso da automação industrial consegue-se apresentar melhorias significativas nas questões de eficiência energética, redução do consumo de lenha, estabilidade do processo produtivo de vapor e a diminuição dos gases emitidos pela caldeira, já que a queima agora se faz de forma controlada pela implantação de um controle automático contínuo em substituição aos meios de operações totalmente manuais e intuitivas. O estudo mostra também que o setor industrial das empresas de produtos lácteos é intensivo no uso de vapor para seus processos fabris.

\section{DISCUSSÃO}

A partir de uma análise dos resultados obtidos com este estudo foi possível verificar similaridades e discordâncias com resultados trazidos anteriormente por outros autores, como por exemplo, Segundo Muraro (2018) foi possível observar que a geração termelétrica oriunda da biomassa pode contribuir significativamente para a diversificação da matriz energética, estabelecendo um desejável equilíbrio hidrotérmico, propiciando maior segurança de fornecimento de eletricidade a nível nacional.

Muraro (2018) expõe ainda que o benefício da utilização de caldeiras de biomassa fornece uma solução sustentável de energia eficiente. Sugere-se como estudos futuros abordar técnicas de melhoria na eficiência energética industrial com uso de biomassa no funcionamento de caldeiras.

Senger (2015), avaliou uma caldeira mista alimentada com lenha em toras e os resultados mostram que a caldeira analisada apresenta um rendimento térmico de $64,3 \%$, que é considerado baixo. Este resultado atribuiu-se ao elevado excesso de ar que diminui a temperatura do gás de combustão e, portanto, a capacidade de transferência de calor para a água da caldeira.

Ainda segundo Senger (2015) a falta de um pré-aquecedor abaixa o rendimento térmico, pois o ar para a combustão entra na temperatura ambiente, com o pré-aquecedor pode-se utilizar a energia contida 
nos gases de combustão realizando uma troca de calor aumentando a temperatura que entra para a combustão, consequentemente aumentando a eficiência térmica do gerador de vapor.

Arruda (2009), também vem contribuir nesse aspecto quando traz em seus resultados as questões ambientais ligadas à poluição do ar, e que no Brasil ainda são muito incipientes. A falta de profissionais qualificados para o gerenciamento destas fontes estacionárias de emissões atmosféricas, ou seja, fontes poluidoras são notáveis e evidentes. As caldeiras em diversas empresas são vistas com um mal necessário para a produção, sem receber a atenção necessária para uma combustão eficiente com menores emissões de gases.

Em relação aos impactos elétricos na rede Saidur et al. (2009), afirma que em todas as faixas de operação o controle por velocidade de rotação é adequado. Ainda que para o carregamento máximo e rotações nominais as estimativas de consumo sejam iguais, de acordo com há a redução dos impactos negativos de partida e parada causados pela ligação direta dos motores a rede elétrica.

Por fim Marafon et al. (2018) conclui que a automação no processo produtivo é geradora de um diferencial competitivo, uma vez que possibilita o aumento de produtividade e flexibilidade dos sistemas produtivos, os quais melhoram a qualidade do produto, trazendo mais uniformidade e conformidade perante as especificações, além de reduzir, tempo da produção e de intervenções humanas, minimizando o número de funcionários e eventuais falhas.

\section{CONCLUSÕES}

Conclui-se que com a substituição do método de controle anterior pelo modelo automatizado mostra-se viável em função da redução da demanda de potência elétrica para suprir o processo de geração de vapor, da economia no consumo de lenha, do aumento da eficiência do equipamento e consequentemente da redução de emissões de poluentes para a atmosfera.

É comprovado através da avaliação financeira e das análise dos custos um retorno financeiro do valor investido de apenas quatro meses e com uma redução no consumo de lenha de $35 \%$ com a aplicação do método de controle por variação de velocidade.

Conclui-se também que os impactos elétricos na rede são minimizados com o uso do controle por velocidade de rotação apresentando uma redução dos impactos negativos de partida e parada causados pela ligação direta dos motores a rede elétrica.

Fatores que encorajam a aplicação desse método de controle automatizado para fins de eficiência energética é a ociosidade dos equipamentos rotativos, que em geral, trabalham com baixo carregamento, e demandando uma potência elétrica praticamente igual à nominal e o aumento da eficiência do equipamento. Já dos pontos de vista econômicos e ambientais são a impactante redução do consumo da matéria prima utilizada para produção de vapor e seus gases poluentes emitidos pela combustão interna das caldeiras a lenha. 


\section{REFERÊNCIAS}

ALAMIA, A.; STRÖM, H.; THUNMAN, H.. Design of an integrated dryer and conveyor belt for woody biofuels. Biomass and Bioenergy, v.77, p.92-109, 2015. DOI: http://dx.doi.org/10.1016/j.biombioe.2015.03.022

ARRUDA, M. Z.. Análise de combustíveis de caldeiras. Monografia (Bacharelado em Engenharia Ambiental) Universidade de Passo Fundo, Passo Fundo, 2009.

BRAND, M. A.; GIESEL G.. Influência da secagem da Biomassa na eficiência de caldeira de cogeração energética. Energ. Agric., Botucatu, v.32, n.2, p.132-140, 2017.DOI: http://dx.doi.org/10.17224/EnergAgric.2017v32n2p132-140

BRASIL. Ministério de Minas e Energia. Reserva Energética Brasileira do Exercício 2015. Brasília: MME, 2016.

IBGE. Instituto Brasileiro de Geografia e Estatística. Indicadores IBGE: estatísticas da produção pecuária. Rio de Janeiro: IBGE, 2015.

KAWÁS, H. B.. Monitoramento das emissões atmosféricas de caldeiras de projetos distintos. Monografia (Bacharelado em Engenharia Ambiental) - Universidade Tecnológica Federal do Paraná, Campo Mourão, 2014.

MAGALHÃES, A. S.; DOMINGUES, E. P.. Aumento da eficiência energética no brasil: uma opção para uma economia de baixo carbono? Economia Aplicada, v.20, n.3, pp.273-310, 2016. DOI: https://doi.org/10.11606/14138050/ea146090

MARAFON, C.; SERVELIN, T.; ANSCHAU, C. T.; SCHNEIDER, A.; PAULA, R.. Benefícios do investimento em automação no processo de empacotamento de farinha de trigo. Anais da Engenharia de Produção, v.2, n.1, p.72-87, 2018.

MORAIS, E. O.. Gestão da energia na indústria: estudo de caso na Braskem. Dissertação (Mestrado) - Universidade
Estadual de Campinas, Campinas, 2015.

MURARO, H.. Queima de biomassa em caldeiras e aquecedores de água. Monografia (Bacharelado em Engenharia Elétrica) - Faculdades Integradas Norte do Paraná, Ponta Grossa, 2018.

TASSI, R.; BRUNA, B. P.D.; CONTESSI, G.; ROSSETTI, M.; ROSSO, P. H. D. F.. Estudo de acionamentos de chaves de partida elétricas e eletrônicas. Rev. Técnico Científica, v.3, n.1, p.504, 2012. DOI:

https://periodicos.ifsc.edu.br/index.php/rtc/article/view/64 $\underline{4 / 451}$

SAIDUR, R.; HASANUZZAMAN, M.; MAMUN, M. A. H.; ABDELAZIZ, E. A.. A study of energy efficiency, economic and environmental benefits of a cooling tower. International Journal of Mechanical e Engenharia de Materiais, v.5, n.1, p.87-94, 2010.

SENGER, R.. Análise do rendimento térmico de uma caldeira mista alimentada com lenha em toras. Monografia (Bacharelado em Engenharia Mecânica) - Universidade Tecnológica Federal do Paraná, 2015.

SOLA, A. V. H.; MOTA, C. M. M.. Melhoria da eficiência energética em sistemas motrizes industriais. Production, v.25, n.3, p.498-509, 2015. DOI:

https://doi.org/10.1590/0103-6513.063311

USDA. United States Departament of Agriculture. Cows milk production and consumption: summary for selected Countries. Washington: USDA Foreign Agricultural Service, 2015.

VERDESOTO, J. P. C.; JÁCOME, F. L. L.. Plan de negocios para la creación de una empresa productora y comercializadora de pellets de madera en el cantón lomas de sargentillo. Tesis (Doctoral) - Universidad de Guayaquil, Guayaquil, 2019.

A CBPC - Companhia Brasileira de Produção Científica (CNPJ: 11.221.422/0001-03) detém os direitos materiais desta publicação. Os direitos referem-se à publicação do trabalho em qualquer parte do mundo incluindo os direitos às renovaç̃es, expansões e disseminações da contribuição, bem como outros direitos subsidiários. Todos os trabalhos publicados eletronicamente poderão posteriormente ser publicados em coletâneas impressas sob coordenação da Sustenere Publishing, da Companhia Brasileira de Produção Científica e seus parceiros autorizados. Os (as) autores (as) preservam os direitos autorais, mas não têm permissão para a publicação da contribuição em outro meio, impresso ou digital, em português ou em tradução. 